OPEN ACCESS

Edited by:

Matthew Collins,

University of Exeter, United Kingdom

Reviewed by:

Weijun Sun,

Shandong Normal University, China Tracey Skillington,

University College Cork, Ireland

${ }^{*}$ Correspondence:

Sandra Cassotta sac@law.aau.dk

Specialty section

This article was submitted to Predictions and Projections, a section of the journal Frontiers in Climate

Received: 23 May 2021 Accepted: 26 August 2021 Published: 22 September 2021

Citation:

Cassotta S (2021) Ocean Acidification in the Arctic in a Multi-Regulatory, Climate Justice Perspective.

Front. Clim. 3:713644. doi: 10.3389/fclim.2021.713644

\section{Ocean Acidification in the Arctic in a Multi-Regulatory, Climate Justice Perspective}

\author{
Sandra Cassotta* \\ Department of Law, International, Environmental and Energy Law at Aalborg University, Aalborg, Denmark
}

The latest IPCC report on Ocean and Cryosphere in a Changing Climate, which builds upon previous IPCC's reports, established a causal link between anthropogenic impacts and ocean acidification, by noting a significant decrease in the Ocean's uptake of $\mathrm{CO}^{2}$, with consequent damage to Earth's ecosystems, which in turn has traceable repercussions on the Arctic Ocean and then from the Arctic to the Planet Earth. The impact of ocean acidification is not only in the biological ecosystem but also on human activities, such as livelihood, food security, socio-economic security and developing communities. However, who can possibly be held ethically/legally responsible for ocean acidification from a climate justice perspective? Since what happens in the Arctic does not stay there, a more systematic law and policy approach to study options and responses in a multi-level, climate- ethical, global perceptive is needed. This paper sheds light on the legal responses available at global, regional and national levels to ocean acidification in a law of the sea and ocean context, both in the Arctic and from the Arctic. The gaps in legal and policy responses in connection to the ethical climate component will be identified. It will shed light on the planetary limits that humanity needs to stay within in order to maintain the future of the Earth. Since it touches upon questions of legal responsibility, on who is responsible for ocean acidification, it will connect to the "supply side" of fossil fuels production and global extraction projects causing anthropogenic $\mathrm{CO}^{2}$ emissions, one of the major causes of ocean acidification. It will also identify which actors, be they "officials" or "non-officials" (such as international organizations, states, regional institutes, Arctic citizens or even forums) should be held ethically responsible, and who should take action.

\footnotetext{
Keywords: ocean acidification, climate change and ocean governance, arctic climate justice and ethics, legal responses to ocean acidification, Arctic Ocean acidification, environmental justice
}

\section{INTRODUCTION AND HYPOTHESES}

Climate change is determining dramatic changes to ocean ecosystems. It poses threats to marine biodiversity and in turn to the entire human dimension associated with it, such as goods, services, livelihoods that the ocean provides. One of these threats is ocean acidification. The latest IPCC Report on Ocean and Cryosphere in a Changing Climate of 2019 established a link between anthropogenic impacts and ocean acidification noting a significant decrease in the Ocean's uptake of $\mathrm{CO}_{2}$ with consequent damage to Earth's ecosystems, which in turn has traceable repercussions on the Arctic Ocean and from the Arctic to the Planet Earth. Ocean acidification is crucial because 
can be conceived as an important indicator of the nexus between climate change and oceans ecosystems under the threat of the current Anthropocene epoch we are living in. However, there is much uncertainty and little knowledge about what the responses should be from a governance perspective, including the role of international law in addressing ocean acidification as an equality and justice problem inherent to climate change rather than just a consequence thereof. This lack of knowledge could have repercussions on mitigation, adaptation and on determining who should be held responsible for ocean acidification.

There are major knowledge gaps in the current literature and weak insight and solutions from a social science perspective. This article intends to contribute to filling this gap by analyzing responses to ocean acidification in international law with special attention to Arctic Ocean acidification from a new angle combining governance and climate justice approaches. The hope is that by discussing whether ocean acidification should be treated as a threat of climate change rather than a concurrent problem will lend greater clarity to the issues in question. Other equally relevant hypotheses are, whether the current instruments of international law are fit to address this issue and if the connection between responses in international law to climate justice arguments could provide new avenues for increased responses such as for example, if there should be a forum in the Arctic Ocean to tackle ocean acidification through the combination of existing agreements and institutions.

The rifts in legal and policy responses in connection to ethical, climate justice components will be identified also by highlighting the planetary limits that humanity needs to stay within in order to maintain the future of the Earth. Since this perspective touches on questions of legal responsibility, liability and on who is actually responsible for ocean acidification it will connect to the supply side of fossil fuels production and global extraction projects causing $\mathrm{CO}_{2}$ emissions as one of the main causes of ocean acidification. It will also individualize which actors should be ethically responsible and who should take action.

In the case of ocean acidification either at general level or more specifically in the Arctic Ocean Acidification context, it is unlikely that a single institution or level of governance or any single set of policies across institutions will be able to tackle the problem of ocean acidification since ocean acidification is a collective action problem occurring in a shared space of global commons. From this angle it is no longer equitable and just that governments alone should be responsible or finance ocean acidification, a problem the latter not involving only the public sectors but also the private sectors and not only official actors but non-official actors, all of which contribute to the large pollution problem. There are no incentives to change "business as usual" and there are several weaknesses in relying upon social institutions of governments, or insurance of civil liability for managing and transferring risks of ocean acidification.

However, theories of climate justice connected with principles of environmental law could suggest approaching the problem form a different angle. From a climate justice perspective damages caused by ocean acidification could be prevented by creating a forum at a regional level, which in the case of Arctic Ocean Acidification could be established at the Arctic Council
(AC) level. A forum of this kind would be able to push for a behavioral change by instilling a new idea of "climate ethical ocean justice" vital to protecting the space of one of the most relevant planetary boundaries of the Earth system.

In order to describe this new angle and to unfold the problem of ocean acidification by operationalizing the hypotheses, in a multi-level holistic vision, this article is structured as follows: the next section sets the field of research by establishing a connection between ocean acidification in the Arctic and from the Arctic both as a threat and consequence of climate change (rather than a concurrent problem) and by explaining how the conceptualization of ocean acidification can be perceived as a planetary boundary within a space that preserves and guarantees an equitable and just future. The subsequent section depicts the multi-regulatory landscape that can be applied with special emphasis on Arctic Ocean Acidification, identifying the gaps in terms of responses with emphasis on the absence of a threshold or boundary line for Ocean Acidification that should not be surpassed in order to bring the level of Ocean Acidification to an acceptable level. In fact, an acidity threshold would be relevant in environmental treaty law in order to establish new standards and thresholds to be incorporated in future law and decision-making policy and legal instruments. The penultimate section connects ethical and climate justice arguments at the core of ocean acidification by establishing directs links between critical environmental theories and environmental law responses that could serve as a foundation for a new holistic governance approach. The concluding section summarizes the implication of the approach for future recommendation and policy perspectives.

\section{OCEAN ACIDIFICATION IN THE ARCTIC AND FROM THE ARCTIC AS A CONSEQUENCE OF CLIMATE CHANGE}

Oceans are the backbone of our planet and play a crucial role in regulating the impact of climate change and partly by absorbing excess of heat, and partly by acting as enormous sinks for carbon emissions. The Intergovernmental Panel on Climate Change (IPCC) assessed that $90 \%$ of the combined heat stored in the climate systems has been absorbed by oceans between 1971 and 2010 [Intergovernmental Panel on Climate Change (IPCC), 2014]. The last IPCC Special Report on the Ocean and Cryosphere in a Changing Climate of 2019 established that oceans have absorbed approximately $30 \%$ of emitted anthropogenic carbon dioxide [Intergovernmental Panel on Climate Change (IPCC), 2019] thus changing the ocean's chemistry and leading to ocean acidification, a process likely to have wide-ranging ramifications for marine biodiversity, biogeochemical processes, the goods and services derived from the oceans and the billions of people depending on it (HarrouldKolieb, 2020).

The impact of ocean acidification is expected to include, but is not limited to, economic losses from a decline in fisheries and tourism, impacts on human health and decreased coastal protection [Arctic Monitoring and Assessment Programme (AMAP), 2018]. Ocean acidification is likely to cause major shifts 
in marine ecosystems, including the loss of most coral reefs globally and a decline of species globally (Eyre et al., 2018).

Geochemical information informs about potential risks to the Arctic and from the Arctic to the rest of the planet. In the Arctic Ocean, the cold surfaces waters absorb $\mathrm{CO}^{2}$ more rapidly than warmer waters, leading to a disproportionately higher fraction of the global net $\mathrm{CO}^{2}$ uptake and climate changes have intensified this susceptibility to ocean acidification [US Geological Survey (USGS), 2012]. Ocean acidification in the Arctic Ocean reduces shell formation, determines habitat loss and less food for predators, thus damaging ecosystems and ecosystem services (Scott et al., 2020). Polar waters will be the first to see the lowering of carbonate ion concentrations to such an extent that shell-forming organisms will not be able to calcify ${ }^{1}$. According to the IPCC Fifth Assessment Report, marine organisms are at risk from progressively lower oxygen levels and higher rates of ocean acidification. It underlines that coral reefs and Polar ecosystems are highly vulnerable ${ }^{2}$.

Because of global warming, science proved the loss of Polar ice and over the last two decades, the Greenland and Antarctic ice sheets have been losing mass, glaciers have continued to shrink almost worldwide, and shrinking Arctic sea ice and Northern Hemisphere spring snow cover have contributed to a decrease in extent ${ }^{3}$.

The Arctic Monitoring Assessment Programme (AMAP) found that ocean acidification, particularly coupled with ocean warming and deoxygenation, will drive changes in the marine ecosystems and impacts Arctic biota and it is likely that ocean acidification will drive changes at a magnitude that will affect the living resources in the Arctic and surrounding regions [Arctic Monitoring and Assessment Programme (AMAP), 2018].

The Earth system is undergoing human-induced changes in a dramatic scale and human interference with natural systems has caused a high level of uncertainty about what the planet will look like in the future (Lim, 2019). The concept of "planetary boundaries" describes the important interdependence of the major environmental challenges faced by the Earth System. Ocean acidification is one of the "planetary boundaries." Planetary boundaries have been defined as a series of biophysical boundaries at the planetary level (Rockström et al., 2009). They include issues such as climate change, biodiversity, freshwater use and ocean acidification. They function as a "safe operating space for humanity," i.e., denoting the planetary-scale limits that human activity needs to stay within in order to maintain the functioning of the Earth's systems in a manner which will allow continued human development (Rockström et al., 2009). Climate change is central to this anthropogenic disruption interlinked with each of the planetary boundaries, including ocean acidification (Minas, 2019). This explains why it is so crucial that law and policy treats the two in synergy: climate

\footnotetext{
${ }^{1}$ Antarctic and Climate Ecosystems Cooperative Research Centre, Position Analysis: $\mathrm{CO}_{2}$ Emissions and Climate Change: Ocean impacts and Adaptation issues. (2008). 5, in Baird et al. (2009).

${ }^{2}$ IPCC Fifth Assessment Report (supra 1).

${ }^{3}$ IPCC Fifth Assessment Report (supra 1 and 5).
}

change and marine environmental protection together and not in disjunction.

The feedback effects of ocean warming and ocean acidification from the Arctic to the rest of the planet may itself aggravate climate change, and the melting of ice (Reid et al., 2009). Ice melting includes the melting of permafrost in the Arctic, resulting in the release of methane which is a green gas some 34 times more powerful than $\mathrm{CO}^{2}$ Occurring over a 100 years period, methane has been released from the seafloor, in turn exacerbating ocean acidification and ultimately entering the atmosphere (Brown et al., 2016). How can the law facilitate the preservation of the planetary boundaries including ocean acidification to facilitate an equitable and just future and preserve the planet in a safe space for our future generations?

The conceptualization of ocean acidification as a planetary boundary within a margin to guarantee to guarantee an equitable and just future for humans and our planet is still not fully understood. There is a chasm of ignorance and lack of regulation from a legal and ethical perspective on how ocean acidification should be conceived and factored in law, decision making associated with marine planning, fisheries management, and area-based protection under the law of the sea (Scott, 2020). Ocean acidification is barely present in environmental justice literature as well.

In the latest IPCC Special Report on Ocean \& Cryosphere in a Changing Climate of 2019, the scientific assessment on ocean acidification notes that the effects of ocean acidification are geographically highly heterogeneous and uncertain but there is an improvement of the understanding of the natural science processes underpinning ocean acidification [Intergovernmental Panel on Climate Change (IPCC), 2019]. From an international law, governance and ethical perspective, ocean acidification has not been included in the Polar Chapter (Chapter 3) of the IPCC Special Report on Ocean and Cryosphere in a Changing Climate of 2019 due to the insufficient amount of literature (at the time of the writing the Report) necessary to elaborate a qualitative and quantitative scientific assessment [Intergovernmental Panel on Climate Change (IPCC), 2019]. Nor has ocean acidification been treated in the theories of environmental justice in connection to either general environmental justice literature, or to specific Arctic Environmental justice literature.

In fact, while the root cause of ocean acidification lies in human policies and behaviors driving society's dependence on fossil fuel, resulting in elevated $\mathrm{CO}_{2}$, there is still a hole/reluctance in the social science literature, specifically in the law and policy area, to engage in ocean acidification (Jagers et al., 2019). Actually, there are still holes in our knowledge about which kind of regimes, policies, legal provisions, and mechanisms can address ocean acidification both in the Polar Regions and the rest of the planet. Provisions of treaty law and regional agreements are applicable but do not address directly the problems of ocean acidification (Oral, 2018). However, it is possible to map the legal regimes applicable to influence mitigation, adaptation and resilience of ocean acidification.

Yet, little is known on how about how society can respond to ocean acidification (Jagers et al., 2019) which is the main reason why possible human responses to ocean acidification can actually 
be considered as a gap of knowledge in term of human responses not only in Chapter 3 on Polar Issues but also in the entire Special Report on Ocean \& Cryosphere in a Changing Climate of 2019 in connection to the other Chapters dealing with regions other than the Polar ones.

Ocean acidification is linked to climate justice and the unequal distribution of global pollution. Ocean acidification is a "collective action problem" of global pollution as there are reasons to believe that the practices from which an unequal distribution of global pollution effects emerge do not benefit every party and inequalities in the distribution of effects and such practices should not be permitted (Skillington, 2017a). Current practices of resource exploitation, especially in the Arctic, do not benefit all peoples but rather undermine the quality of life of a global majority.

\section{LEGAL RESPONSES AT GLOBAL AND REGIONAL LEVEL}

The legal landscape responding to ocean acidification is composed of a regime complex of multi-regulatory systems of sources of law and policy at global, regional and national level characterized by hard law, soft law, standards, and decisionmaking tools. The multi-layered and deformalized structure where different actors (both officials and non-officials) operates highlight the possible synergistic and interactive application of the different sources of law and policy to ocean acidification.

The three main regimes that hold prominence in ocean acidification classified in "global regimes and regional regimes" are from: (1) the climate change regimes, (2) the marine pollutions regimes, and (3) the biodiversity regimes. Ocean acidification is thus not regulated by one single regime but governed by a "regime complex" where different sources of law and policy interact and overlap without coordination even though several mitigation strategies on ocean acidification have been initiated through multilateral cooperation (Jagers et al., 2019).

At the global level, despite the increasing knowledge about ocean acidification, there are no provisions explicitly aimed at regulating ocean acidification and no treaties combatting ocean acidification.

The most relevant frameworks existing at global level that are also applicable to the Arctic Ocean are the United Nations Convention on the Law of the Sea (UNCLOS) $)^{5}$, the United Nations Convention on Climate Change (UNFCCC) ${ }^{6}$, the Paris

\footnotetext{
${ }^{4} \mathrm{~A}$ "regime complex" is a collection of governance arrangements that are linked together in the sense that they address matters related to a common issue area or spatially defined region but that are not hierarchically related in the sense that they all fit within some well-defined institutional architecture. The theorists of this way of thinking about governance have focused on cases like the regime complex for plant genetic resources and the regime of climate change. For "complex regimes," see Oran (2012).

${ }^{5}$ United Nations Convention on the Law of the Sea (UNCLOS), 10 December 1982. ${ }^{6}$ United Nations Framework Convention on Climate Change, (UNFCCC), 9 May 1992.
}

Agreement ${ }^{7}$, the Biodiversity Convention (CBD) ${ }^{8}$ although there are other relevant developments that can be considered such as for example within the typology of the atmospheric pollution global regimes.

\section{Global Regimes}

Amongst the main global pollution regimes, the 1982 United Nations Convention on the Law of the Sea (UNCLOS) is a legal framework within which all activities in the oceans and seas must be carried out. UNCLOS is of strategic importance for global, regional and national level action and cooperation in the marine sector. Within this framework, the Arctic Ocean can be seen as an ecosystem to be protected. Some environmental provisions of UNCLOS are relevant for ocean de-acidification but also with the view of applicability to the Arctic Ocean.

UNCLOS's part dedicated to environmental protection in general is Part XII where pollution of the marine environment has been defined in general terms in Article 1 (1) 4 which includes ocean acidification effects ${ }^{9}$. Art. 194 of UNCLOS provide that States shall take all measure necessary to prevent, reduce and control pollution of the marine environment from any source ${ }^{10}$. Paragraph 5 of Art. 194 is of particular relevance regarding ocean acidification in the Arctic as it deals with vulnerable areas ${ }^{11}$.

UNCLOS requires States to take those measures necessary to prevent, reduce and control pollution of the marine environment and to adopt national laws and regulation to prevent and reduce pollution of the marine environment through the atmosphere. This includes the introduction by man of energy into the marine environment, which drives the increase in energy stored in the oceans and its associated impacts, including oceans warming, sea level rise, marine species redistribution, impacts on ecosystems. The notion of "pollution of the marine environment" therefore includes the direct introduction of anthropogenic carbon dioxide into the marine environment, a cause of ocean acidification.

Since there is no coordination and linkage between conservation and management measures and the impact of climate change as present, the UNCLOS convention is

\footnotetext{
${ }^{7}$ Paris Agreement on Climate Change, UN Doc. FCCC/CP2015/L.9/Rev.1, 12 December 2015.

${ }^{8}$ Convention on Biological Diversity (CBD), 5 June 1998.

${ }^{9}$ Art. 1 (1) 4 of UNCLOS states "Pollution of the marine environment means the introduction by man, directly or indirectly, of substances or energy into the marine environment, including estuaries, which results or is likely to result in such deleterious effects as harm to living resources and marine life, hazards to human health, hindrance to marine activities including fishing and other legitimate use of the sea, impairment of quality for use of sea water and reduction amenities".

${ }^{10}$ Art. 194 of UNCLOS specify that states shall take all measures necessary to prevent, reduce and control pollution of the marine environment from any source. Sources of pollution are for example: pollution from land-based sources, pollution from or through the atmosphere, pollution by dumping, pollution from vessels, pollution from seabed activities, pollution from other installations and services operating in the marine environment and pollution from activities in the Area. With the term "measures" contained in this article, it is understood that it is inclusive of those necessary to protect and preserve rare or fragile ecosystems as well as the habitat of depleted, threatened or endangered species and other forms of marine life.

${ }^{11}$ Article 194 (5) states "The measures taken in accordance with this Part shall include those necessary to protect and preserve rare or fragile ecosystems as well as the habitat of depleted, threatened or endangered species and other forms of marine life".
} 
supplemented by more detailed regimes, including those regulating dumping at sea and land and atmospheric source marine pollution both of which are applicable to ocean acidification and to some degree to the Arctic Ocean. An example is the 1972 London Convention ${ }^{12}$ and its 1996 London Protocol ${ }^{13}$, negotiated to replace the 1972 London Convention both aiming at preventing the pollution of the sea by the dumping of waste or other matters liable to create hazards to human health, and harm living resources, including marine life. The convention also applies to the dumping of active waste in parts of the Arctic Ocean.

With regards to the global climate regimes, some of the most relevant regimes dealing with ocean acidification are the United Nations Framework Convention on Climate Change (UNFCCC), and the Kyoto Protocol (Kyoto Protocol), recently replaced in 2020 by the Paris Agreement of 2015. The UNFCCC convention has clear implications for the Arctic Ocean as the effects of global warming could have a devastating impact upon various types of ice. Not only would the release of fresh water from the ice cap increase a rise in the sea level but it would also have an impact on the marine ecosystem. The Arctic States ${ }^{14}$ are large, industrial states, which have significant temperate lands in addition to their Polar claims and interests. The problem of climate change is truly global, one of which states need to cooperate collectively. All these climate change regimes focus on reducing the Greenhouse Gas Emissions (GHGs) that cause ocean acidification. However, ocean acidification had not been examined scientifically in detail at the time of negotiations of these two treaties-the UNFCCC and the Kyoto Protocol. There is no mention of ocean acidification in either of them. Nor is any mention of the problem of ocean acidification in the recent Paris Agreement.

Article 2 of the UNFCCC is relevant for ocean acidification stating that the object is the "stabilization of greenhouse gas emissions in the atmosphere at a level that would prevent dangerous anthropocentric interference with the climate system to, inter alia, allow ecosystems to adapt naturally to climate change, to ensure that food production is not threatened". However, ocean acidification has frequently been perceived more as a threat to climate change rather than an effect of it (Harrould-Kolieb, 2019). This separation of the two phenomena has resulted in placing ocean acidification outside of the mandate of the UNFCCC and contributed to creating a gap in global governance with no multilateral agreements having jurisdiction over mitigation of the increasing of ocean acidification. The strategy of framing ocean acidification as a separate problem to climate change is reflected in its absence from the work of the UNFCCC. Some legal scholars have suggested how to reframe the existing UNFCCC mandate including adopting a new Protocol in order to fill the gap of

\footnotetext{
${ }^{12}$ Convention on the Prevention of Marine Pollution by Dumping of Wastes and other Matters, 29 December 1972.

${ }^{13}$ Protocol to the Convention on the Prevention of Marine Pollution by Dumping of Waste and other Matters 1996 (as amended in 2006).

${ }^{14}$ The Arctic States are Canada, Denmark (including Greenland and the Faroe Islands), Sweden, Russia, and the United States.
}

governance and reframe ocean acidification as an effect of climate change (Kim, 2012).

The other regime relevant for ocean acidification is the Paris Agreement, adopted 23 year later after the UNFCCC Convention, in 2015. The Paris Agreement seeks to strengthen the implementation of the UNFCCC, especially its objective in Article 2. One of the most interesting aspects of the Paris agreement is the attempt to quantify clearly the ambiguous objective of Article 2. According to Article 2(1), the Paris Agreement aims to strengthen the global responses to the threat of climate change, including "holding the increase in the global average temperature well below $2 \mathrm{C}$ above pre-industrial levels." However, it still remains unclear what impact this temperature objective will have on ocean acidification.

Another provision of the Paris agreement relevant to ocean acidification is Article 2.1(a) stating "...global peaking of greenhouse gas emissions as soon as possible... and rapid reduction thereafter in accordance with best available science, so as to achieve a balance between anthropogenic emissions by sources and removals by sinks of greenhouse gases by the second half of this century". In that sense some attempts have been made to understand how to respond in law to ocean acidification with mitigation work including the adoption of a separate target for $\mathrm{CO}^{2}$, the setting of a goal for ocean acidification alongside that of temperature, the possible inclusion of mitigation goals for ocean acidification into the National Determined Contributions (NDCs) and a formal recondition of ocean acidification as a concurrent threat to climate change rather than its effect.

However, there is no threshold of "unacceptable" pH change that could establish a standard to be integrated into treaties and other legal tools, including the UNFCCC. Establishing a threshold or boundary line for ocean acidification that should not be surpassed is much needed. It is still not known what is the exact amount of $\mathrm{CO}_{2}$ that should be reduced (like emission reductions pathways) in order to bring the level of ocean acidification to an "acceptable level."

The IPCC Special Report on Ocean and Cryosphere of 2019 does not contain such predictions establishing a direct link between the $1.5^{\circ} \mathrm{C}$ and ocean acidification. There are indeed direct links between cumulative $\mathrm{CO}_{2}$ emissions, the level of global warming (and thus remaining carbon budgets), and ocean acidification but not between the $1.5^{\circ} \mathrm{C}$ and ocean acidification.

According to Article 2(1), the Paris Agreement "aims to strengthen the global response to the threat of climate change," including by holding the increase in the global average to limit the temperature increase to $1.5^{\circ} \mathrm{C}$ above pre industrial levels."

However, the crucial question is: do we know what impact this temperature objective (the $1.5^{\circ} \mathrm{C}$ ) will have on ocean acidification? In other words, do the goals of the temperature targets accurately take into account ocean acidification or $\mathrm{pH}$ levels as part of the reduction of risks and impact of climate change? There are indeed direct links between cumulative $\mathrm{CO}_{2}$ emissions, the level of global warming (and thus remaining carbon budgets), and ocean acidification but there is no direct system of linkage between temperature targets and the reduction of carbon dioxide concentrations in the atmosphere with the $\mathrm{pH}$ level in the oceans. There is no certainty that keeping the 
temperature below $1.5^{\circ} \mathrm{C}$ will guarantee that the level of ocean acidification will be kept at an acceptable level.

The reframing of ocean acidification as a threat of climate change rather than as aspect concurrent with the impact of climate change, as suggested by study of Harrould-Kolieb (2019), would change the focus for action within the UNFCCC as it no longer would be imperative that the Conference of the Parties (COP) acknowledge ocean acidification as being contained within the mandate of UNFCCC to be addressed alongside climate change.

Rather, ocean acidification as an adverse effect of climate change could become an integral aspect in understanding the complete picture of global climate change and the health of the climate system including the threshold's gap. Therefore, it could inform policy choices on emission limits and adaptation strategies. In this way, ocean acidification would no longer be excluded from the work of the Paris Agreement and would no longer would be seen as an additional problem to climate change but rather its attenuation. Furthermore, scientific advances in terms of assessing thresholds for ocean acidification could even become a new parameter by which to measure the success of efforts to combat climate change in terms of risks and impacts.

As to Biodiversity Conservation Regimes, the Convention on Biological Diversity $(\mathrm{CBD})^{15}$ was established with the three main goals: the conservation of biodiversity, the sustainable use of the components of biodiversity, and the fair and equitable sharing of benefits arising from the commercial and other utilization resources. The importance of the Precautionary principle ${ }^{16}$ in the convention is relevant to ocean acidification in the effort to ensure that the absence of scientific certainty is not used as justification for failing to take appropriate measures to safeguard biodiversity. The CBD therefore pays special attention to the problem of ocean acidification given the severe effects that it can have on marine organisms and ecosystems of the planet. The CBD Convention is significant globally because of its Article 8 regarding the establishment of the management of protected areas which concerning the Polar Regions is important for the enhancement of protected areas. In the Arctic, there is also scope for a closer assessment of the development of a more extensive system of marine protected areas.

As to other developments for example within the typology of the atmospheric pollution global regimes, the 1999 Protocol to Abate Acidification, Eutrophication and Ground-level Ozone ${ }^{17}$ sets ceilings and national emissions standards for four pollutants (sulfur, nitrous oxides, volatile organic compounds (VOCs) and ammonia). Art. 2 of the Protocol states that a central objective is to ensure that a critical load of acidity is not exceeded, including in marine environments. This provides an important example of "acidity threshold" in an environmental treaty, and could represent a source of inspiration for the new standards and

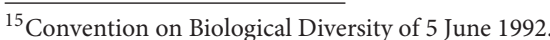

${ }^{16}$ The Precautionary principle aims to provide guidance in the development and application of international environmental law where there is scientific evidence of uncertainty. See de Sadeleer (2010).

${ }^{17}$ Protocol to Abate Acidification, Eutrophication and Ground level Ozone, 20 November 1999.
}

thresholds to be incorporated in future laws and decision-making treaty law processes.

\section{Regional Regimes}

In the Arctic, ocean acidification is dealt under the umbrella of the Arctic Council (AC) the central instrument of scientific cooperation in the Arctic Region that is soft law in nature. The main role of the AC (Arctic Council) is to protect the Arctic environment. In the $\mathrm{AC}$, there are four core working groups ensuring that the Arctic development takes place responsibly in respect of the environment ${ }^{18}$. One of the working groups deals with marine environment and livelihood: the Arctic Monitoring and Assessment Programme (AMAP) also treats ocean acidification. The AMAP monitors and measures levels of anthropogenic pollutants with the purpose of assessing their effects on the Arctic environment by establishing an Arctic Monitoring Assessment Task Forces, the Secretariat of which is based in Norway.

The AMAP is a scientific organism that mainly elaborate reports in details on the status of Arctic ecosystems and identifies the main causes of change by evaluating the impacts and effects of climate change in the Arctic Ocean not only in the fauna and flora but also on the local population.

According to the final results and evaluations, the AMAP prepares a series of recommendations directed to the Arctic States in order to reduce the risks on ecosystems. The AMAP anticipates that ocean acidification, particularly if coupled with ocean warming and deoxygenation, will drive changes in marine ecosystems and impacts on Arctic biota. According to the latest AMAP report of 2018, these changes pose risks to commercial, subsistence and recreational fisheries, as well as to the provision of other ecosystems services in the region ${ }^{19}$. The AMAP couples anthropogenic ocean acidification to the component of $\mathrm{pH}$ reduction caused by human activity.

Another piece of regional soft law related of Arctic Ocean acidification is the Kiruna Declaration ${ }^{20}$ adopted under the Swedish Chairmanship at the AC. In the Kiruna Declaration, Arctic Ocean acidification was taken into consideration together with other significant Arctic Scientific Studies including Arctic Biodiversity Assessment, Arctic Ocean Review, and the Agreement on Marine Oil Pollution and Preparedness and Response in the Arctic ${ }^{21}$. In the Kiruna Declaration, Arctic Ocean acidification required the AC to continue to take action on mitigation and adaptation and to monitor and assess the state of Arctic Ocean acidification.

An important regional regime applying to Arctic Ocean Acidification is the 1992 Convention for the Protection of the Marine Environment of the North East Atlantic (OSPAR

\footnotetext{
${ }^{18}$ The four working groups of the AC are: the Arctic Monitoring and Assessment Programme (AMAP), the Conservation of Arctic Flora and Fauna (CAFF), the Protection of the Arctic Marine Environment (PAME) and the Emergency Prevention and Response (EPPR).

${ }^{19}$ AMAP. (2018). 49.

${ }^{20}$ Kiruna Declaration, on the Eight Ministerial Meetings of the AC, MM08-15 May 2013-Kiruna, Sweden.

${ }^{21}$ Agreement on Cooperation on Marine Oil Pollution, Preparedness and Response in the Arctic of 15 May 2013.
} 
Convention) $)^{22}$. The OSPAR Convention is the main regime between 15 States of the western coasts and the catchment of Europe, which together with the European Union (EU), cooperate to protect the marine environment of the North- East Atlantic. The OSPAR regime aims at identifying environmental threats and organizing programmes and measures to combat environmental threats effectively.

In the OSPAR Convention, the link between prevention and precaution is ensured by Art. 2 (2) imposing wide-ranging obligations on States parties to "take all possible steps to prevent and eliminate pollution". Pollution is defined broadly as in the UNCLOS Convention as "the introduction by man, directly or indirectly, of substances or energy into maritime area which results, or is likely to result, in hazards to human health, harm to living resources and marine ecosystems, damage, to amenities or interference with other legitimate uses of the sea". Ocean acidification falls directly into the above-cited OSPAR definition of pollution because it is a process caused by the indirect introduction by humankind of $\mathrm{CO}_{2}$ into the ocean and it is likely to result in environmental damage to marine ecosystems.

The purpose of the OSPAR convention is thus to protect the ecosystems from the threat of pollution and problems that could jeopardize habitat health, which is particularly sensitive in the Arctic Ocean. For more than 30 years, this instrument has been able to significantly reduce radioactive waste, phosphor, and heavy metals, regulate offshore activities, and provide a precise evaluation of the status of the water's health.

The regulation of Arctic Ocean acidification is ensured by Art. 2 (2) with the relevance of the Precautionary principle that links prevention and precaution where preventative measures are to be taken when there are "reasonable grounds for concerns... even whenever there is not conclusive evidence of a causal relationship between the inputs and the effects". Climate change is one of seven designated work areas of the OSPAR Commission and it is worth noticing that in 2006 the OSPAR Commission published a report on ocean acidification that included a detailed consideration of its marine environmental impacts. The OSPAR Commission also adopted a decision to prohibit placement of $\mathrm{CO}_{2}$ on or above the seabed.

At the EU level, several instruments have been developed, both of primary or secondary legislation aiming to protect the marine environment ${ }^{23}$. The preferred instruments adopted by the EU legislator to combat ocean acidification are the directives that require member states to transpose these measure at national level to make them directly applicable. For example, Sweden which is both an Arctic State and a EU member State, has implemented a number of EU directives by adopting legal acts

\footnotetext{
${ }^{22}$ Convention for the Protection of the Marine Environment of the North-East Atlantic, 22 September 1992, in force 25 March 1998 (“OSPAR Convention”).

${ }^{23} \mathrm{~A}$ number of Directives are applicable to Ocean acidification and also to the Arctic Ocean, such as for example Directive (EU) 2000/60/EC Water Framework; Directive (EU) 2003/87/EC Emission Trading Scheme; Directive (EU) 2008/50/EC Ambient Air Quality; Directive (EU) 2008/56/EC Marine Strategy Framework; Directive (EU) 2008/Reduction of national emissions of certain atmospheric pollutants.; Directive (EU) 2009/28/EC Measures for promotion of energy from renewable sources; Directive (EU) 2012/27/EC Energy Efficiency; Directive (EU) 2014/89/EU Marine Spatial Planning.
}

at national level such as the Air Quality Ordinance and the Environmental Code. However, not all the EU member states have implemented laws on ocean acidification to this level.

There are actually no studies from a bottom-up approach showing how EU member states have mitigated ocean acidification. Arctic States member of the European Economic Area $(E E A)^{24}$ zone do not document a strong research and legislative framework to combat ocean acidification in spite of the fact that ocean acidification observed across the Arctic Ocean has become increasingly apparent, which indicates that more work is needed in this area with regards to ocean acidification (Galdies et al., 2020).

EU Member States action on ocean acidification shows that the current state of European national policies and legislation addressing the ocean acidification problems is, where existent, uncoordinated. Although the ocean acidification problem is acknowledged at higher levels of governance, such as for example at the European Commission level, it is greatly diluted at EU member states level (Galdies et al., 2020). Even though the EU has adopted a number of multilateral agreements, they only address a fraction of ocean acidification. More effective and stronger legal responses to curb ocean acidification problems, including the establishment of an acceptable threshold at EU level to be coordinated with a global ocean acidification threshold are needed.

The EU attempt has been more directed at regulating climate change in general rather than focusing on ocean acidification. The recent European Green Deal ${ }^{25}$ has not dedicated special attention to ocean acidification. However, in the field of research, an important effort has been conducted by a recent Horizon 2020 research, the INTAROS, targeting the Arctic Ocean ${ }^{26}$.

Overall, rather than focusing on ocean acidification, all the existing previously mentioned regimes only address fractions of the problems and are solely concerned with measures aimed at mitigating and lowering $\mathrm{CO}_{2}$ emissions and climate change. Even if there were a system of multi-regulatory governance applicable to ocean acidification in general and specifically also applying to the Arctic Ocean acidification context, it seems that there is a lack of coordination between the different regimes.

Ocean acidification has a global nature that requires cooperation among states at all the scales and layers of governance to address it. The law is without any doubt a promising instrument to respond to ocean acidification because it aims at changing the behavior of states and industries, and individuals, but more cooperation between the different layers of governance and actors at all the levels of governance is

\footnotetext{
${ }^{24}$ The European Economic Area (EEA) was established via the Agreement on the European Economic Area, an international agreement which enables the extension of the EU's single market to member states of the European Free Trade Association (EFTA). The EEA links the EU member states and three EFTA states (Iceland, Liechtenstein, and Norway) into an internal market governed by the same basic rules.

${ }^{25}$ European Green Deal" (Communication). COM. (2019). 11 December. 640 final. ${ }^{26}$ The overall objective of INTAROS is to develop an integrated Arctic Observation System (iAOS) by extending, improving and unifying existing systems in the different regions of the Arctic. See more at: Available online at: https://cordis europa.eu/project/id/727890 (accessed May 5, 2021).
} 
necessary. Multiple instruments are applicable to remedy ocean acidification in general but they are not designed to address ocean acidification specifically and to take into account the diversity of ocean acidification impacts in different geographic areas, such as the Arctic Ocean, presents. Even when some aspects are taken into account in some pieces of legislation at global level that are applicable to the regional level and to the Arctic Ocean, there is no coordination between the regional (Arctic Ocean) and the global regimes when it comes to regulating ocean acidification and no coordination between the global regimes and the regional regimes.

\section{ETHICAL AND CLIMATE JUSTICE ARGUMENTS AT THE CORE: THE CRITICAL ENVIRONMENTAL THEORIES CONNECTED TO ENVIRONMENTAL LAW}

This section explores how ethical and justice arguments shared by the society are interconnected with environmental law and can shape legal and policy responses to globally deteriorating climate conditions of ocean acidification. The practice from which an unequal distribution of global pollution effects emerges such as like the depletion of common global resources (i.e., the air or the oceans), is unjust.

According to Rawls (2017), in its theory of the history of justice, inequalities perpetuated by environmentally destructive practices should not be allowed to continue, as there is reason to believe that these practices do not benefit all parties. Among these practices, resource exploitations do not benefit all peoples but rather undermine the quality of life of a global majority. An appropriate climate ethic takes into consideration collective action problems affecting the Arctic, like global warming and increasing ocean acidification. All this environmental degradation is taking place by human hands acting as isolated individuals, business companies, or states.

In the Arctic, resource access and competition for oil and gas, fishing or mining are the main causes of $\mathrm{CO}_{2}$ emissions, and also reverberate at planetary level, as these resources exploitations are the central cause of global warming. Climate change in the Arctic is one of the greatest threats to the fragile Arctic marine environment causing ocean acidification and melting of sea-ice. Ethical and climate justice arguments should guide how ocean acidification can be talked about and perceived from a legal justice perspective and how such a perspective regarding ocean acidification could alleviate global warming.

There are three main kinds of ethical responsibilities that could arise as a consequence of climate change (Caney, 2009). These ethical responsibilities are: (1) a responsibility to mitigate climate change; (2) to attribute responsibility to enable those hit hardest by climate change to adapt (developing countries), and (3) once liability established, to compensate those affected by the threat. In all these possibilities, the common denominator is how to distribute the burden of responsibility and decide if this responsibility should be distributed among official actors (state and international organizations) or non-official actors (such as corporations, individuals, NGOs, groups of interests, or lobbies) or shared by all at once since climate change is a global, collective problem, such as ocean acidification. Also, the capacity of oceans and marine ecosystems to adapt and function under $\mathrm{pH}$ levels of acidification can be framed as a global collective action problem. This kind of global collective action problem can be understood as the "Tragedy of Commons" (Hardin, 1968). In the same way, oceans and the climatic atmosphere are not inexhaustible. The amount of clean air on earth is, for example, not without limit. The Tragedy of Commons predicts a gradual overexploitation of common pool resources, including oceans and atmospheric resources, which include an unlimited decrease of the $\mathrm{pH}$ levels of ocean acidification with deteriorating, environmental and human damaging consequences.

At the core of critical environmental theories applicable to ocean acidification is the discourse regarding co- responsibility for the deteriorating effect on humanity of climate change (such as crop failure, drought, flooding, and ocean acidification). Therefore, ocean acidification is perceived as one of the severe deteriorating effects of climate change.

New standards are directly needed (Skillington, 2017a). One solution is to apply and connect ethical and climate justice criteria. From and environmental law perspective, there are three main factors that can be taken into account to design a model of ethical and climate justice to ocean acidification applicable also more specifically to Arctic ocean acidification which are: to attribute responsibility, minimize uncertainty, establish environmental liability combined with a compensation fund approach

Concerning the attribution of responsibility, certain societies have polluted with cumulative emissions for long a period by conducting certain activities, that caused damage to the atmosphere and to the oceans, determining ocean acidification (often defined as "past historical pollution"). These damages includes not only damages to the environment but also to communities (such as for example to indigenous people or communities depending on natural resources and ecosystem managements at sea). According to principles of environmental law, norms and values, the wrongdoers (i.e., states, or international organizations polluting and increasing ocean acidification) should assume responsibility with the consequential compensation to harm others as a consequence of a wrongful act such as for example the violation of primary rules (i.e., treaties) and admit circumstances excluding responsibility for wrongful acts. There are however, a lot of uncertainties on how far is it possible to consider the historical damaging period and which sectors (transport, energy, heating, or food) contributing to the increase of ocean acidification. Another difficulty is due to the fact that the extent to which different activities contributed to acidification vary substantially between different geographical localities, and to identify responsibility in a "global commons" areas ${ }^{27}$ may be a hard task.

\footnotetext{
27 "Global commons" in international law are areas that do not fall within the jurisdiction of any one country and are defined as "international or global commons." The notion of global commons posits that there are limits to national sovereignty in certain parts of the world and that these are areas should be open to use by the international community but closed to exclusive appropriation by treaty
} 
Therefore, minimizing uncertainties becomes relevant because increase the possibility to activate responsibility. For example, there is uncertainty as to which actors may also affect the impacts of ocean acidification via interacting stressors because ocean acidification could be aggravated also by other stressors such as eutrophication, wastewater discharge, or fishing and some other actors may also contribute to ocean acidification at multiple scales to make marine ecosystem more vulnerable to the impacts of ocean acidification.

Environmental liability is just one aspect of responsibility and arises out from activities not prohibited by international law that cause damage. The aim of liability is the prevention of environmental damage and reparation of victims instead of stopping the activity and has more a preventative function. The relevant actors are states or international organizations. However, there is still the need to understand what is the clear terminological distinction between the terms "responsibility" and "liability."

Establishing liability as a consequence of environmental damage is also related with the problem that the environment (in this case the sea or ocean) which is a public goods or res propriare, or res communes, or res nullus is not belonging to anyone. Liability requires the existence of "standards" of justice. Violations of these standards may be subject to legal investigation, which differs according to the common law systems (based on tort law) and civil law systems. There are three main types of civil liability criteria as a consequence of environmental damage: (1) fault based, (2) strict liability, and (3) absolute liability (Cassotta, 2012). In this article, only the two types of liability will be considered as relevant for the purpose of this section. The typical situation where fault liability apply is when subject $\times$ damage subject $y$ with the existence of the subjective element of culpa, and $\mathrm{x}$ must repair. However, in environmental law civil liability when applied to environmental damage is completely disrupting this situation because the good belonging to subject $y$ (in our case the environment that has been damaged) is not susceptible to be object of ownership as it is a public good and does not belong to anyone. Under a strict liability regime the victims of the environmental damage are facilitated since they do not have to prove culpa of the potential wrongdoer in order to receive compensation. Strict liability is generally adopted in case of involving activities likely to have harmful consequences even if conducted with due care or due diligence or in respect of the normal criteria for standards or tolerability. In case of fault liability, the injured parties (y) of the environmental damage are not facilitated since they must prove the culpa of the potential wrongdoer $(\mathrm{x})$ in order to be compensated for damages. A certain development in terms of environmental justice is when civil liability as a consequence of environmental damage is connected to the Polluter-pays principle.

According to Kramer's definition, the Polluter-pays principle is "firstly an economic principle belonging to the public sphere, and has to be understood as expressing the costs of environmental impairment, damage and clean-up that should

or customs. Examples of "global commons" areas are: the High Seas, Antarctica, Outer Space and the Atmosphere. See Redder and Hughes (2008). not be borne via society's taxes, but by those persons who caused pollution" (Krämer, 2007).

However, there are several uncertainties concerning the relationship between the Polluter-pays principle and the sphere of civil liability such as: who the polluter is, what is the environmental damage and how much compensation should be paid. Environmental law still has to evolve in order to make sovereign states liable for environmental damage, ocean acidification included.

There are still issues in relation to causation or probabilistic causation relevant to climate change such as the nexus between the author of the damage and the event which is difficult to prove and cumulative emissions or diffuse pollution which is the problem emerging when the damage is not a consequence of a single damaging situation. In the latter case, the difficulty is to determine the source of pollution and the percentage of responsibility of each polluter, and establish if there was joint, several responsibility, and the percentage of responsibility attributable to each. Recent rulings have progressed with the ordering to the Netherlands to reduce GHGs emissions by 2020 and there is progress with climate modeling to better determine and identify the source of pollution. However, causation is still a non-linear and challenging problem. The ethical and climate justice problem is huge since cumulative climate harms is generated by many states and industrial actors, all engaging in pollution practices, all increasing ocean acidification.

The Courts of Hague attempt to hold states accountable for not meeting $\mathrm{CO}_{2}$ emissions targets, as the general understanding is that high polluting states are jointly and several responsible for global warming and ocean acidification of the oceans as well as the reduction of subsurface oxygen levels affecting the growth of marine phytoplankton, coral reefs and fish stocks (Skillington, 2017a). Agents inflicting the increase of ocean acidification has not to be attributed to states only but also to corporate actors, especially industries in the sector of fossil fuels, which are emitters of GHGs emissions.

The idea of preventing or moderating negative consequences of ocean acidification suggests that someone takes responsibility for limiting actions of individuals that increase common risks. This could be done, for example, by transferring the uncompensated damages of ocean acidification to the top fossil fuel companies. This perspective suggests that it is the fossil fuel companies that increase climate changes impacts determining ocean acidification. However, governments deal with risks and externalities as well ${ }^{28}$. In the face of ocean acidification, it is unlikely that only the public sectors and governments are solely responsible but also the private sector which often has no incentives to change its "business as usual" practices. It would not be equitable and just to expect governments to be the primarily responsible parties and financiers of negative effects of ocean acidification. An innovative solution in that sense could be to transfer the financial risks of ocean acidification to fossil fuel

\footnotetext{
${ }^{28}$ The concept of "externalities" refers to the activity of the potential polluter. The potential polluter is in this way forced to also include in its costs for production, the costs that could emerge from environmental damage through a mechanism called “internalization." Cropper and Oates (1992).
} 
companies. The proposal in this line of reasoning could be to establish an ocean acidification fund as has been done in the past to clean up and compensate victims for a number of hazardous activities such as for example, for oil pollution spills, toxic chemical and asbestos contaminants and opt for a "compensation fund for ocean acidification."

The compensatory fund approach is based on precedents in law where it is not possible to identify the author of the damage to the environment and thus funds are created where upstream taxes, levies or excises are imposed on the introduction of harmful substances. Important examples of compensatory fund approach are: (1) US Superfund scheme and CERCLA (Comprehensive Environmental Response, Compensation and Liability Act of 1980$)^{29}$; (2) three international conventions on oil pollution which are the 1992 International Convention on Civil Liability for Oil Pollution Damage [International Oil Pollution Compensation Fund (IOPC Fund), 1992]; the 1992 International Convention on Civil Liability for Oil Pollution Damage (1992 CLC Fund) ${ }^{30}$; and the 2003 International Supplementary Fund for Compensation for Oil Pollution Damage ${ }^{31}$, and (3) the US oil pollution regime called 1990 US Oil Pollution Act (OPA) ${ }^{32}$ All these regimes have in common that they be based on precedents for upstream levies, taxes and excises on feedstock.

CERCLA establishes a "Superfund" financed primarily by excise taxes on petroleum and chemical feedstock, to enable governments to pay for the clean-ups of hazardous chemicals. The reason why CERCLA is extremely interesting for a possible applicability in a legal framework for loss and damage caused by ocean acidification is precisely that it can compensate even if the polluters are not identifiable at the origin. The aim of this fund is to compensate from damage deriving from atmospheric pollution to the subject or parties that cannot find any solutions from the civil liability mechanism. This is exactly the case of CERCLA. In CERCLA there is no need to demonstrate causation, as what is relevant is to identify the cause of harm and attributes strict liability. Compensation funds can be combined with strict liability as it occurs in numerous international conventions, as all those identified in the previous paragraphs.

Other examples are those of the triadic regime previously identified the (1) 1992 CLC Fund, the (2) 1992 IOCP Fund, and the (3) the 2003 International Supplementary Fund for Compensation for Oil Pollution Damage). Under the international law of treaties, international conventions protecting the environment contain compensation schemes on transboundary pollution. In order to design a regulatory framework for loss and damage applicable to ocean acidification, some elements of each can be picked up. The relevance of these conventions with respect to ocean acidification is especially due to the possibility to apply the Polluter-Pays principle. In general,

\footnotetext{
${ }^{29} 42$, U.S.C. ss. 9601 et seq., as amended through P.L. 107-377, 31 December 2002, see also at https://www.epa.gov/superfund/superfund-cercla-overview.

${ }^{30}$ London (UK), 27 November 1992, in force 30 May 1996, see at https://www.imo. org/en/About/Conventions/Pages/International-Convention-on-Civil-Liabilityfor-Oil-Pollution-Damage-(CLC).aspx.

${ }^{31}$ See at https://iopcfunds.org/

${ }^{32}$ Available online at: https://www.epa.gov/enforcement/oil-pollution-act-opaand-federal-facilities
}

liability and state liability rules determine whether the Polluterpays principle really applies or if it is just a "principle in the air" and the regimes on oil pollution can fill this gap because these regimes are examples of "canalization" 33 of liability.

In particular, the triadic regime provides three layers of compensation available for victims of pollution damage. The first layer of compensation derives from the 1992 CLC Fund, which covers damage caused by oils of a state party of the convention and where both joint and several strict liability are placed on the owner of the ship from which the pollution escaped. The second layer of compensation arises with the 1992 IOCP Fund providing supplementary funding, where compensation available under CLC is insufficient. As in CERCLA, compensation payments are financed by the contributors; private companies or other entities (private or public). The third layer is the 2003 International Supplementary Fund for Compensation for Oil Pollution Damage, which is also financed by contributors. The 1990 US OPA established the Oil Spill Liability Trust Fund which like CERCLA allows trustees to spend up US 2.5 billion for removal costs and damages for each incident and the interesting aspect in connection to ocean acidification is that it provides parties to be liable also for the diminution in the value of natural resources and not only on the costs of restoration. However, environmental law factors need also to be connected to ethical and climate justice criteria in order to design a model of ethical and climate justice to ocean acidification and establish new standards.

The design of a proposed fund, as discussed previously can overcome climate ocean injustice created by ocean acidification, overcome the weakness of civil liability to compensate for ocean acidification. In a more concrete way, by combining CERLA to the global and US oil pollution regimes, the fund should include issues of: (1) identification of liable parties, which are the companies that should be levied for their annual historical production of fossil fuel, (2) identification of the claimants which are the victims vulnerable to ocean acidification that can bring claims against the fund by a state party claiming on behalf of its affected citizens, (3) establishment of a levy without limitation, like in the case of the 1992 IOPC Fund and CERLA, and (4) provide parties liable also for the diminution in the value of natural resources and not only on the costs of restoration, as in the case of the OPA, even if the quantification of the damage cause by ocean acidification could be difficult to calculate.

Existing theories of climate change justice mainly focus on corrective and distributive justice approaches aiming at attributing responsibility to developed countries to take the lead on climate change (Lyster, 2015). The main theories of climate change justice that are applicable to ocean acidification are classified in three types: (1) Contribution to the problem as corrective approach based on the Polluter-pays principle (2) ability to pay principle as distributive justice and a (3) hybrid

\footnotetext{
33 "Canalization" means to "canalize" or "channel liability" toward the person who is in control of the activity "ex ante." In case of oil pollution and pollution at the sea, the person who is in control of the ship or the ship owner or in case of nuclear pollution, it will be the operator of the nuclear power plant.
} 
approach merging corrective approach and distributive justice (Lyster, 2015).

These theories can be interconnected with environmental law principles, and concepts. They can be applied specifically to Arctic Ocean acidification for an understanding of how climate justice for the Arctic Marine Environment could shape the behavior of actors such as states, business sectors, industries or individual and how actors should think and act differently.

\section{Contribution to the Problem-A Corrective Approach}

The contribution to the problem in terms of corrective justice is how to connect civil liability to the Polluter-pays principle to minimize the uncertainties caused by unsolved enigmas such as the identification of the author of pollution, quantification of the damage, compensation and problem of a time factor, or the so-called remoteness of the damage or historical pollution or emissions.

The obligation to pay for climate change (and the impacts on ocean acidification) should be bridged with both the capacity to pay in terms of income and responsibility to pay (historical emissions) in the interests of equity (Skillington, 2017a). A corrective justice approach is based on the idea that it is the countries that mostly caused pollution in terms of global cumulative emissions that should contribute to the costs. Ethical justice in the corrective approach is based on the concept that developed countries have the ethical responsibility to reduce their emissions given their cumulative, diffuse and "past historical pollution" and correct the negative impacts determining ocean acidification. The determination of responsibility for climate harm is based on evidence generated by the IPCC on existing patterns of GHGs emissions among states.

\section{Ability to Pay Principle-A Distributive Justice}

The ability to pay principle in the idea of distributive justice that derives from the claim that developed countries have a greater capacity to cover the costs of mitigation and adaptation to climate change. The distribute justice approach differs from the corrective approach because it does not focus on who contributes to the problem and who is responsible but rather on who has the capacity to rectify the harm and who can mitigate the problem. What is a need is to establish a fair system of climate change mitigation that tackle the different levels of inequalities existing in individual countries. The assessment of capacity to pay links state's responsibility with individual with responsibility leading to the possibility to change individual behavior and shape actions. Distribute justice does focus on weighing and calculating the capacity to pay and responsibility to pay in terms of the distribution of income and emissions across populations within each state. The ability to pay and distributive justice have the potential to enhance a type of responsibility that changes consumption behaviors, habits, and engages the awareness to conserve the environment and pay the price for not polluting, including the price of for not increasing ocean acidification.

\section{A Hybrid Approach-A Corrective and Distributive Approach Leading to Legal Cosmopolitanism}

The hybrid approach combines and integrates the corrective approach with the distributive justice approach by integrating "who contributes to the problem" with "who should pay." The approach takes into consideration different problems related to negative externalities, causality link, and uncertainties. Property rights at seas are often poorly defined especially outside the Exclusive Economic Zone (EEZ) and emissions of $\mathrm{CO}_{2}$ have impacts far away from their sources. National policies could provide incentives to internalize the costs. In order to account for the true costs of carbon on global warming, these must also be globally coordinated, address all the sources of carbon and provide for an account for climate change including changes due to $\mathrm{CO}_{2}$ and their ocean acidification effects (Turley and Gattuso, 2012).

However, true costs of carbon on global warming are not only uncoordinated they do not even cover all the emitting industries and do not account for ocean acidification (Sterner and Coria, 2019). This approach also requires that the financial benefits agreed to in multilateral negotiations reach individuals and are not simply distributed to states. This approach has, therefore "cosmopolitan implications" deriving from the cosmopolitan justice view of justice being a global responsibility rather than state-based. Legal cosmopolitanism is concerned with the legal status of individuals as human beings, rather than citizens of specific states.

Cosmopolitan heritage is debated in light of a range of pressing concerns, including persisting inequalities, the rapid loss of biodiversity, the depletion of resources including ocean acidification, the loss of home, livelihood and natural habitat, unmitigated climate change that impact adversely on the region of the Arctic (Skillington, 2017b). Kant's political theory bases cosmopolitan law on the need to protect the rights and dignity of all individuals (Kant, 1975). This view could instill a new idea to establish an obligation on fossil fuel producers to contribute to a Fund of climate ocean acidification disaster response, which might also be regarded as "cosmopolitan."

There is an undeniable link attributing ocean acidification to the "supply side" of fossil fuels production and global extraction projects causing anthropogenic $\mathrm{CO}_{2}$ emissions. Over the past 200 years, the world's oceans have absorbed more than 15 billion metric tons of carbon dioxide emitted from human activities.

The atmospheric concentration of $\mathrm{CO}_{2}$ has increased because of the burning of fossil fuel such as coal, gas, and oil along with land use change such as the conversion of natural forest into crop production. Continuing with this "business- as-usual" scenarios, in the end of the century the surface waters of the ocean could be nearly 150 percent more acidic, resulting in a $\mathrm{pH}$ that the oceans haven't experienced for more than 20 million years.

The polluting exploitation behavior typical of the current Anthropocene Era has contributed to the degradation of the oceans and the marine environment. Climate responsibilities extend well-beyond official actors, such as states, national governments, International Organizations or institutions. 
Also non-official actors such as sub-national governments, corporations, utilities and individuals are polluting agents and liable for ocean acidification contributing damage not only to the marine environment but also to local communities. In societies that are completely interlinked to the marine environment and which are strongly dependent on marine biodiversity, ocean acidification alters not just the chemistry of oceans but also their livelihood. Many indigenous and coastal communities, such as those across the Arctic, for example, have felt the effects on the food-web in the Arctic Ocean which is very sensitive.

Therefore, a significant increase of the population of one species or the disappearance of another could have dramatic damaging and loss effects on the entire Arctic marine ecosystem and on indigenous people which are part of the ecosystem. Nonofficial actors are therefore viewed as having an obligation to address climate change and decrease ocean acidification.

Societal perceptions that fossil fuels companies bear distinctive climate responsibilities are reflected in the existence of movements of reaction and climate lawsuits against plans of exploitations pushing for a shift in behavior toward a transition from fossil fuel to non-polluting green activities in line with the goals of the Paris Agreement.

Climate change litigation is one example of legal actions against fossil fuel companies' plans to exploit and the governments allowing exploitations licenses for fossil fuel's extractions. One example, in the Arctic is with the issuance in 2016 by the Norwegian Ministry of Petroleum and Energy of an offer of 10 new production licenses in the $23 \mathrm{rd}$ licensing round on the Norwegian continental shelf under the Barents Sea (Stokke, 2020). Five months later three Norwegian environmental organizations filed a suit against the government. In 2017 and 2018, for example more than a dozen US cities and counties and the state of Rhode Island filed suits against several investorowned fossil fuel companies seeking to hold them liable for their contribution to the damages from sea level rise and increasingly extreme weather that climate change is imposing on local communities.

Recent research has quantified the contribution of $\mathrm{CO}_{2}$ and $\mathrm{CH}_{4}$ emissions traced to the products of major fossil fuel companies and cement manufacturers to global, atmospheric $\mathrm{CO}_{2}$ surface temperature and seal level rise. This means that major industrial carbon producers can be linked to responsibility aspects connected to societal considerations as a consequence of ocean acidification. Loss and damage in regions that are affected by ocean acidification in the context of climate change and other stressors is now identifiable which can open the path to future advancements in terms of attributing responsibility to major fossil fuel producers for the current and near-term risks of further loss and damage to human communities dependent on marine ecosystems and fisheries vulnerable to ocean acidification.

However, the extent and severity of future damage as a consequence of ocean acidification and climate change on the marine species and ecosystems, and the human communities dependent upon them will continue to be determined by the future course of plans to exploit natural resources by the fossil fuels industries. For example, in the Arctic Ocean, which is characterized by high fishing potentials, high value fisheries such as those harvesting Alaska red king crab and Atlantic sea scallop, decreases as a consequence of ocean acidification as assessed by projections, eventually become apparent in the next 20 and 30 years when effects exceed natural variations together with other projections.

Specific climate impacts and damages due to ocean acidification are attributed not only to states entities but also to non-official actors mirroring a situation of oceanic atmospheric injustice caused by a carbon society that undermines the idea of climate democracy and increases a situation of climate ocean injustice that will lead the Arctic Ocean and the Oceans in general to a point of non-return in terms of sustainability, marking the collapse of one of the most relevant planetary boundaries.

The design of a proposed fund, as discussed previously can overcome climate ocean injustice created by ocean acidification, overcome the weakness of civil liability to compensate for ocean acidification. In a more concrete way, by combining CERLA to the global and US oil pollution regimes, the fund should include issues of: (1) identification of liable parties, which are the companies that should be levied for their annual historical production of fossil fuel, (2) identification of the claimants which are the victims vulnerable to ocean acidification that can bring claims against the fund by a state party claiming on behalf of its affected citizens, (3) establishment of a levy without limitation, like in the case of the 1992 IOPC Fund and CERLA, and (4) provide parties liable also for the diminution in the value of natural resources and not only on the costs of restauration, as in the case of the OPA, even if the quantification of the damage cause by ocean acidification could be difficult to calculate.

\section{DISCUSSION AND CONCLUSION}

The issue of responsibility concerning ocean acidification is actually profoundly linked to fossil fuel in the Arctic Ocean where we witnesses a real race for natural resource' extraction. The huge oil reserves there attract the oil companies to extract. These companies have plans to extract natural resources like oil and gas until 2030. It is very difficult for governments to make a break with these plans because there are enormous interests at stake. However, if we persist in the extraction of all the resources mankind wants to take the result will unquestionably be increasing ocean acidification. Taking into account science predictions, the temperature will rise 4 degrees Celsius by 2030. Not only states are responsible for ocean acidification but also isolated individuals, companies, corporations acting in the market.

The increasing of ocean acidification due to fossil fuel activities interacting with other activities that are exploiting and depleting the marine environment, contradicts the concept of sustainable development, and the goals of the Paris Agreement. It will contribute to ice melting which will determine Sea Level Rises (SLR) and in turn will have a direct impact outside the Arctic, such as for example on the Pacific Islands and the sinking of these Islands such as for example the Small Island and Developing States (SIDS). 
Only by taking ocean acidification into account as a collective action problem and linking it to issues of responsibility by multiple actors as a threatening consequence of climate change, and with an appropriate ethical and climate justice perspective, will it be possible to find solutions. With regards to Arctic ocean acidification, a smart system of energy transition involving all the actors that are responsible for ocean acidification to make them change behavior should be organized at regional level, i.e., at the Arctic Council level. Here a forum of discussion, together with a special Fund for compensation financed by those who are the most responsible for ocean acidification, could represent an avenue to avoid the erosion of one of the most relevant planetary boundaries of our Earth system. The fund could be an innovative vehicle for transferring the financial risks of ocean acidification to fossil fuel companies by establishing synergistic linkages between the different levels of multi-regulatory scale, which are now absent. A fossil-fuel Fund for Arctic ocean de-acidification could set the foundation to connect legal, environmental principles to climate justice, which could serve as a test case for a general funding of global de-acidification at a global level.

\section{REFERENCES}

Arctic Monitoring and Assessment Programme (AMAP) (2018). AMAP Assessment. Arctic Ocean Acidification. AMAP (2018), 49.

Baird, R., Simonson, M., and Stephens T. (2009). Ocean acidification: a litmus test for international law. Carbon Clim. Law Rev. 3, 459-471.

Brown, P. J., Sanders, R., McDonagh, E., Henson, S., Best, A. I., Poulton, A. J., et al. (2016). "Impacts and effects of ocean warming on carbon management including methane hydrates," in Explaining Ocean Warming, Causes, Scale, Effects and Consequence, eds D. Laffoley and J. M. Baster. Full Report. IUCN, 380-384.

Caney, S. (2009). Justice and the distribution of greenhouse gas emissions. J. Glob. Ethics 5, 125-146. doi: 10.1080/17449620903110300

Cassotta, S. (2012). "The liability directive from an historical -comparative perspective", in Environmental Damage and Liability Problems in a Multilevel Context - The Case of the Environmental Liability Directive (Wolters Kluwer, Law and Policy Series), 40-50.

Cropper, M. L., and Oates, W. E. (1992). Environmental Economics: a survey. J. Econ. Lit. 30:678.

de Sadeleer, N. M. (2010). The precautionary principle in EU law. Aansprakelijkheid Verzekering En Schade. 5, 173-184.

Directive (EU) 2003/87/EC Emission Trading Scheme. DIRECTIVE 2003/87/EC OF THE EUROPEAN PARLIAMENT AND OF THE COUNCIL of 13 October 2003 Establishing a Scheme for Greenhouse Gas Emission Allowance Trading Within the Community and Amending Council Directive 96/61/EC (OJ L 275/32).

Directive (EU) 2008/Reduction of national emissions of certain atmospheric pollutants. DIRECTIVE 2008/50/EC OF THE EUROPEAN PARLIAMENT AND OF THE COUNCIL of 21 May 2008 on Ambient Air Quality and Cleaner Air for Europe (OJ L 152).

Directive (EU) 2000/60/EC Water Framework. DIRECTIVE 2000/60/EC OF THE EUROPEAN PARLIAMENT AND OF THE COUNCIL of 23 October 2000 Establishing a Framework for Community Action in the Field of Water Policy (OJ L 327)

Directive (EU) 2008/50/EC Ambient Air Quality. Directive 2008/50/EC of the European Parliament and of the Council of 21 May 2008 on Ambient Air Quality and Cleaner Air for Europe (OJ L 152).

\section{AUTHOR CONTRIBUTIONS}

The author confirms being the sole contributor of this work and has approved it for publication.

\section{FUNDING}

This article represents a deliverable for the Horizon 2020 Project on Arctic Environmental Justice Horizon 2020-Research and Innovation Programme Grant Agreement No. 869327 (JUSTNORTH) Granted by the European Union (EU) and to which SC is Institutional Partner for the Working Package 6 (WP6) in Law and Policy. In particular, this article bridge WP6 with Working Package 1 (WP1) of the above JUSTNORTH Research Project, which is discussing Critical Theories of Climate Justice.

\section{ACKNOWLEDGMENTS}

I would like to thank Valérie Masson-Delmotte, Hans-Otto Pörtner, and Lisa Levin for their exchange of views in the physical oceanography parts.

Directive (EU) 2008/56/EC Marine Strategy Framework. Directive 2008/56/EC of the European Parliament and of the Council of 17 June 2008 Establishing a Framework for Community Action in the Field of Marine Environmental Policy (OJ L 164).

Directive (EU) 2009/28/EC Measures for promotion of energy from renewable sources. DIRECTIVE 2008/50/EC OF THE EUROPEAN PARLIAMENT AND OF THE COUNCIL of 21 May 2008 on Ambient Air Quality and Cleaner Air for Europe (OJ L 152).

Directive (EU) 2012/27/EC Energy Efficiency. DIRECTIVE 2012/27/EU OF THE EUROPEAN PARLIAMENT AND OF THE COUNCIL of 25 October 2012 on Energy Efficiency, Amending Directives 2009/125/EC and 2010/30/EU and Repealing Directives 2004/8/EC and 2006/32/EC (L 315/1).

Directive (EU) 2014/89/EU Marine Spatial Planning. DIRECTIVE 2014/89/EU OF THE EUROPEAN PARLIAMENT AND OF THE COUNCIL of 23 July 2014 Establishing a Framework for Maritime Spatial Planning (L 257/135).

Eyre, B. D., Cyronak, T., Drupp, P., De Carlo, E. H., Sachs, J. P., and Andersson, A. J. (2018). Coral reefs will transition to net dissolving before end of century. Science 359, 908-911. doi: 10.1126/science.aao 1118

Galdies, C., Bellerby, R., Canu, D., Chen, W., Garcia-Luque, E., Gašparović, B., et al. (2020). European policies and legislation targeting ocean acidification in European waters - Current state. Mar. Policy 118:103947. doi: 10.1016/j.marpol.2020.103947

Hardin, G. (1968). The tragedy of commons. Science 162, 1243-1248. doi: $10.1126 /$ science.162.3859.1243

Harrould-Kolieb, E. R. (2019). Reframing ocean acidification in the context of the United Nations Framework Convention on Climate Change (UNFCCC) and Paris Agreement. Clim. Change Policy 19, 1125-1238. doi: 10.1080/14693062.2019.1649994

Harrould-Kolieb, E. R. (2020). The UN Convention on the Law of the Sea: a governing framework for Ocean Acidification? RECIEL 257, 257-270.

Intergovernmental Panel on Climate Change (IPCC) (2014). Climate Change Synthesis Report 40. Hereinafter IPCC Fifth Report.

Intergovernmental Panel on Climate Change (IPCC) (2019). Special Report on the Ocean and Cryosphere in a Changing Climate, Chapter 3. IPCC.

International Oil Pollution Compensation Fund (IOPC Fund) (1992). Available online at: https://iopcfunds.org/ (accessed September 3, 2021). 
Jagers, S. C., Matti, S., Crépin, A. S., Langlet, D., Havenhand, J. N., Troell, M., et al. (2019). Societal causes of and responses to, ocean acidification. Ambio 48, 816-830. doi: 10.1007/s13280-018-1103-2

Kant, E. (1975). Perpetual Peace and Other Essays. Translated by T. Humprey. Indianapolis, IN; Cambridge: Hackett Publishers.

Kim, R. E. (2012). Is a new multilateral environmental agreement on ocean acidification necessary? Rev. Eur. Commun. Int. Environ. Law 21, 243-258. doi: $10.1111 /$ reel.12000.x

Krämer, L. (2007). EC Environmental Law. London: Thomson Sweet and Maxell, 27-28.

Lim, M. (2019). Charting Environmental Law Futures in the Anthropocene. Adelaide, SA: Springer.

Lyster, R. (2015). Climate Justice and Disaster Law. Cambridge: Cambridge University Press, 125-132.

Minas, S. (2019). "The ocean-climate nexus in the unfolding anthropocene: addressing environmental challenge through international law and cooperation, Chapter 7," in Charting Environmental Law Futures in the Anthropocene, ed M. Lim (Adelaide, SA: Springer).

Oral, N. (2018). Ocean acidification: falling between the legal cracks of UNCLOS and the UNFCCC? Ecol. Law Q. 45, 9-45. doi: 10.15779/Z38SB3WZ68

Oran, Y. (2012). Building an international complex regime for the arctic: current status and next steps. Polar J. 2, 391-407. doi: 10.1080/2154896X.2012.735047

Rawls, J. (2017). “A theory of justice. 1999," in Climate Justice and Human Rights, eds T. Skillington (New York, NY: Palgrave; Harvard University Press), 41-72.

Redder, M. E., and Hughes, M. P. (2008). Global Commons and Domain Interrelationships: Time for a New Conceptual Framework? Strategic Forum; National Defense University, SF No. 259, 1-11.

Reid, P. C., Fischer, A. C., Lewis-Brown, E., Meredith, M. P., Sparrow, M., Andersson, A. J., et al. (2009). Chapter 1. Impacts of the oceans on climate change. Adv Mar Biol. 56, 1-150. doi: 10.1016/S0065-2881(09)56001-4

Rockström, J., Steffen, W., and Noone, K. (2009). A safe operating space for humanity. Nature 461, 472-475. doi: 10.1038/461472a

Scott, C., Doney, D., Shallin, B., Sarah, R., and Kristy, J., Kroeker. (2020). The impacts of ocean acidification on marine ecosystems and reliant human communities. Annu. Rev. Environ. Resour. 45, 83-112. doi: 10.1146/annurev-environ-012320-083019
Scott, N. K. (2020). Ocean acidification: a due diligence obligation under LOCS Int. J. Mar. Coast. Law 35, 382-408. doi: 10.1163/15718085-BJA10005

Skillington, T. (2017a). From Climate Justice and Human Rights. Chapter 1. Climate Justice. Working Package 1. Grant Horizon 2021 JUSTNORTH. New York, NY: Palgrave.

Skillington, T. (2017b). “Cosmopolitan justice: an outline," in Climate Change Justice and Human Rights (New York, NY: Palgrave MCmillan), 41-72.

Sterner, T., and Coria, J. (2019). Policy Instruments for Environmental and Natural Resources Management, 2 Edn. New York, NY: RFF Press.

Stokke, Ø. (2020). "Chapter 2. Thinking like an ocean: a climate ethic for the arctic marine environment," in Arctic Marine Sustainability - Arctic Maritime Business and the Resilience of the Marine Environment, eds E. Pongrácz, V. Pavlov, and N. Hänninen (Springer Nature, Springer Polar Science), 38.

Turley, C., and Gattuso, J. P. (2012). Future biological and ecosystem impacts of ocean acidification and their socioeconomic-policy implications. Curr. Opin. Environ. Sustain. 4, 278-286. doi: 10.1016/j.cosust.2012.05.007

US Geological Survey (USGS) (2012). Studying Ocean Acidification in the Arctic Ocean. April. Fact Sheet, 2012-3058.

Conflict of Interest: The author declares that the research was conducted in the absence of any commercial or financial relationships that could be construed as a potential conflict of interest.

Publisher's Note: All claims expressed in this article are solely those of the authors and do not necessarily represent those of their affiliated organizations, or those of the publisher, the editors and the reviewers. Any product that may be evaluated in this article, or claim that may be made by its manufacturer, is not guaranteed or endorsed by the publisher.

Copyright (c) 2021 Cassotta. This is an open-access article distributed under the terms of the Creative Commons Attribution License (CC BY). The use, distribution or reproduction in other forums is permitted, provided the original author(s) and the copyright owner(s) are credited and that the original publication in this journal is cited, in accordance with accepted academic practice. No use, distribution or reproduction is permitted which does not comply with these terms. 